\title{
A Novel Modeling of Molten-Salt Heat Storage Systems in Thermal Solar Power Plants
}

\author{
Rogelio Peón Menéndez ${ }^{1}$, Juan Á. Martínez ${ }^{2}$, Miguel J. Prieto ${ }^{2, *}$, Lourdes Á. Barcia ${ }^{3}$ and \\ Juan M. Martín Sánchez ${ }^{4}$
}

1 Group TSK, 33203 Gijón, Asturias, Spain; E-Mail: rogelio.peon@tsk.es

2 Department of Electrical Engineering, Universidad de Oviedo, 33203 Gijón, Asturias, Spain; E-Mail: jamartinez@uniovi.es

3 González Soriano S.A., 33420 Llanera, Asturias, Spain; E-Mail: 1urdesalbar@gmail.com

4 ADEX, S.L., 28031 Madrid, Spain; E-Mail: juanms@adexcop.com

* Author to whom correspondence should be addressed; E-Mail: mike@uniovi.es;

Tel.: +34-985-182-567; Fax: +34-985-182-138.

External Editor: Jean-Michel Nunzi

Received: 25 July 2014; in revised form: 16 September 2014 / Accepted: 8 October 2014 /

Published: 17 October 2014

\begin{abstract}
Many thermal solar power plants use thermal oil as heat transfer fluid, and molten salts as thermal energy storage. Oil absorbs energy from sun light, and transfers it to a water-steam cycle across heat exchangers, to be converted into electric energy by means of a turbogenerator, or to be stored in a thermal energy storage system so that it can be later transferred to the water-steam cycle. The complexity of these thermal solar plants is rather high, as they combine traditional engineering used in power stations (water-steam cycle) or petrochemical (oil piping), with the new solar (parabolic trough collector) and heat storage (molten salts) technologies. With the engineering of these plants being relatively new, regulation of the thermal energy storage system is currently achieved in manual or semiautomatic ways, controlling its variables with proportional-integral-derivative (PID) regulators. This makes the overall performance of these plants non optimal. This work focuses on energy storage systems based on molten salt, and defines a complete model of the process. By defining such a model, the ground for future research into optimal control methods will be established. The accuracy of the model will be determined by comparing the results it provides and those measured in the molten-salt heat storage system of an actual power plant.
\end{abstract}


Keywords: solar thermal power plant; thermal energy storage; process modeling

\section{Introduction}

Thermal solar plants use mirrors to focus the energy coming from the sun on a point where a heat transfer fluid (HTF) is heated; this is usually referred to as concentrated solar power (CSP) [1,2]. The fluid heated in this way is then used in a thermodynamic cycle (usually a water-steam cycle) to produce electricity. Most thermal power stations nowadays use parabolic trough collector (PTC) technologies [3-5] to heat some kind of oil, which plays the role of HTF. This is a very mature technology that is being used, for instance, in the 160-MW power plant that Sener, Acciona and TSK are installing in Ouarzazate, Morocco, and which has an overall cycle efficiency of $40 \%$. This paper deals with this kind of power plants.

However convenient as it may seem, solar energy is only available during certain times of day and the electric power this energy can originate might not match that demanded. Therefore, as well as defining an efficient and economical way to produce electric energy, it is also important to store thermal energy in an efficient and economical way so that it can be used when demanded [6]; this is usually referred to as thermal energy storage (TES).

Although several possibilities have been defined to carry out this TES (kinetic energy storage, potential energy storage, pressure energy storage, chemical energy storage), most plants store thermal energy without previous conversion into other type of energy, thus increasing the overall efficiency of the process. There are also different ways to store thermal energy [7]: directly storing HTF before the turbine supply, storing pressurized vapor [8] or storing thermal energy in an external system. The latter is the solution most widely implemented, especially when high energy is to be stored. Most TES use an external system based on molten salt $[9,10]$, which has been identified as the preferred possibility, especially when nitrate salt is used for the storage medium [11]. In this type of systems, the molten salt typically moves between two tanks: a cold-salt tank and a hot-salt tank. When necessary, the HTF will meet the molten salt in a heat exchanger so as to give rise to the heat transfer required in each case: from the HTF to the molten salt or vice versa [12,13]. It must be noticed that, although the technology used in these heat exchangers is mature, there is not a standard disposition for such exchangers.

Given the complexity of thermal solar power plants, a distributed control system (DCS) must be implemented with control variables and algorithms distributed between several controllers [14,15]. This is a very common solution for all types of complex industrial processes. The molten-salt system is usually managed by a specific controller within the DCS. The DCS receives the field signals requested by the TES control system and sends them to this specific controller, which generates the adequate actions. Although many different algorithms have been used in the literature to control heat transfer in exchangers (mainly predictive control algorithms [16-18], but also neural networks [19], controllers designed using the coefficient diagram method (CDM) [20] and control based on fuzzy models [21,22] or on nonlinear models $[23,24]$ ), the control of TES systems is somewhat different, and the special features related to heat transfer in this kind of systems result in proportional-integral-derivative (PID) control systems being most commonly used. 
Some authors pursue optimization of the power plant as a whole [25-27] and state that, because energy storage systems represent only one part of a greater energy system, it is critical to consider the entire system, and not the storage in isolation [28]. In this paper, however, the thermal energy storage process is considered by itself. This alternative is also used in other works $[1,25,29]$ that consider that each process in the power plant should be individually optimized in order to have an overall operation as optimum as possible.

Optimization of the TES process in order to make it become as efficient and economical as possible involves developing more sophisticated control systems and, in order to do so, it is necessary to have an accurate model of the process associated to the performance of TES systems. In most cases, the TES system is simply defined in terms of how many hours the plant can rely on it [25]; some others [30] define the parameters to be included in an online simulation software [31]; others [1,29] describe the equations related to these systems but either they do it too thoroughly or they are again only used to determine how much the solar share of the power plant can be increased as a function of the storage capability of the system.

The goal of this paper is to develop a model that can be used by designers to optimize the energy storage control without the need to interfere with normal plant operation. Experience has shown that, although a correct estimation of temperature values is important, the main feature of the model to develop must be its capability to accurately represent the delays introduced by the large elements in the system, since these delays must be considered when designing the control strategy. The precision of the model developed will be tested by comparing the results it provides to those measured in the molten-salt heat storage system of an actual power plant.

It must be pointed out that, even though the heat exchanger is a very important part of the TES, this paper does not aim to provide a very accurate model of this single device. As far as the performance of the TES system is concerned, it is not so important to have great accuracy in the temperatures estimated by the model as it is to have the model provide reliable information of the times involved in the TES operation.

\section{Materials and Methods}

In order to accurately model the TES process, its operation modes must be first clearly defined. Conventional systems consist of: one cold salt tank, one hot salt tank, an HTF-salt exchanger, pumps (to move the molten salt from one tank into the other), pipes and control valves. Figure 1 shows a typical schematic that includes a single train formed by three exchangers and Table 1 shows the control elements (and their respective control variables) identified in this schematic; flow directions in this schematic depend on whether the heat storage system is being charged (HTF flows from the hot side to the cold side, salt flows from the cold tank to the hot tank) or discharged. The model to develop must include the set points of the control variables as inputs, since the state of the elements they control will determine the performance of the TES.

Similarly, the model must have several outputs that allow users checking whether the response of the system is the expected one or not. Process outputs are monitored in actual systems by means of several sensors placed at the inputs and outputs of the heat exchanger as shown in Figure 2. 
These elements, which are summarized in Table 2, are the model outputs to consider during the different operation modes of the energy storage system.

Figure 1. Schematic of a thermal energy storage (TES) system.

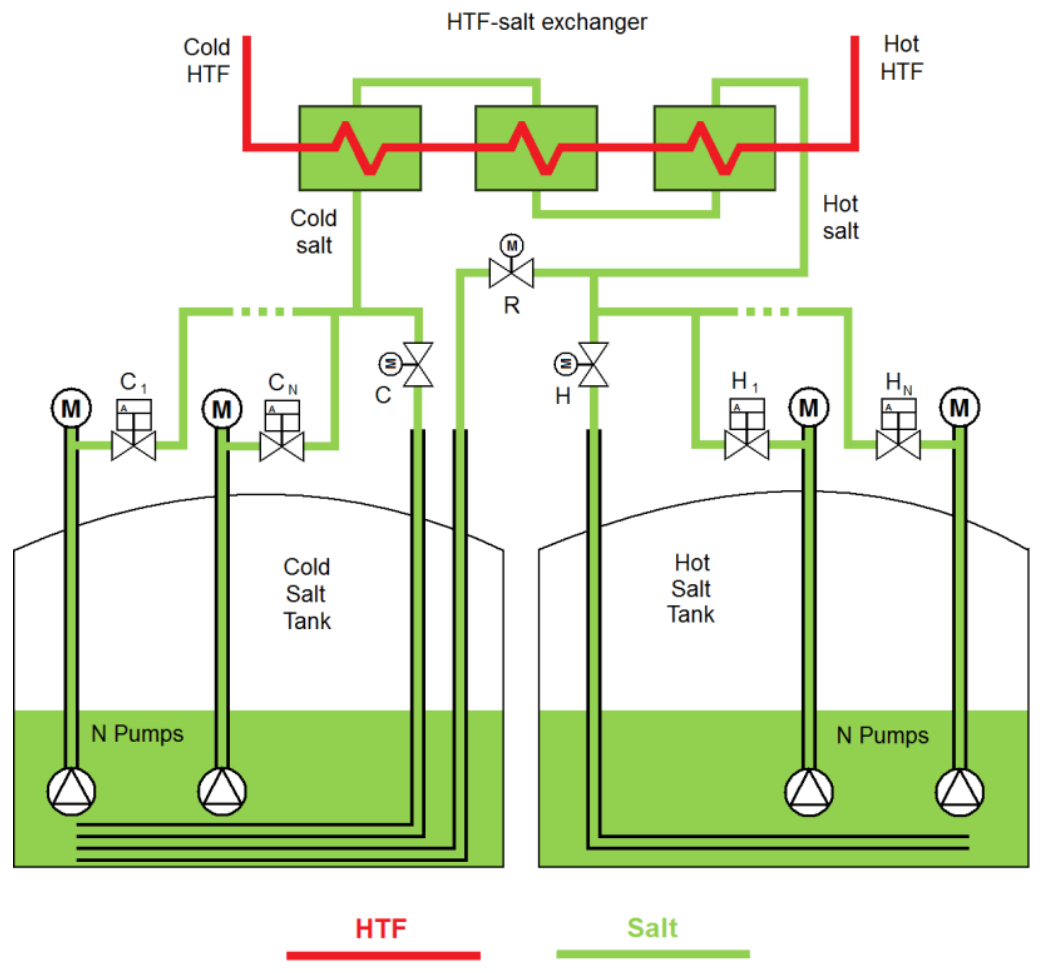

Figure 2. Schematic of the heat exchanger.
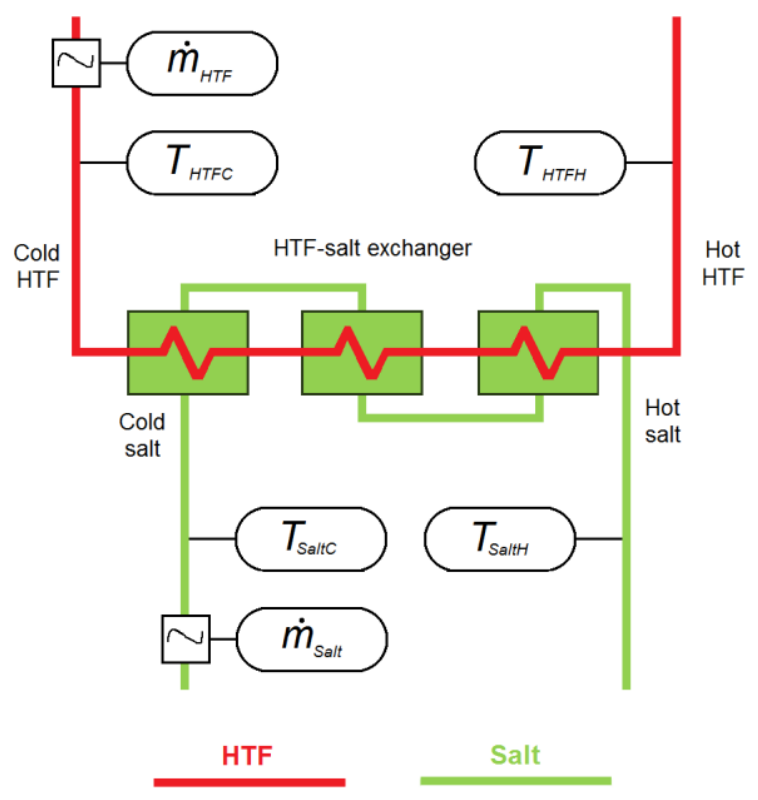

The disposition of the TES in a thermal solar plant is schematized in Figure 3. This or similar schematics are widely accepted in literature $[1,25,32]$ to represent the three main circuits in plants of this kind: the solar field (SF), through which the heat transfer fluid (HTF) circulates, the power block, which circulates water and steam, and the TES system. 
Table 1. Control elements.

\begin{tabular}{ccccccc}
\hline & \multicolumn{2}{c}{ Control Element } & & \multicolumn{3}{c}{ Control Variable } \\
\cline { 1 - 3 } \cline { 5 - 6 } Symbol & Component & Description & & Symbol & Magnitude & Unit \\
\hline $\mathrm{C}_{1}$ to $\mathrm{C}_{\mathrm{N}}$ & Pump & Cold-salt pump & & $\mathrm{SPV}_{\mathrm{C} 1}$ to $\mathrm{SPV}_{\mathrm{CN}}$ & Velocity & $\mathrm{rpm}$ \\
$\mathrm{C}$ & Valve & Main valve in the cold-salt tank & & $\mathrm{SPO}_{\mathrm{C}}$ & Opening & $\%$ \\
$\mathrm{H}_{1}$ to $\mathrm{H}_{\mathrm{N}}$ & Pump & Hot-salt pump & & $\mathrm{SPV}_{\mathrm{H} 1}$ to $\mathrm{SPV}_{\mathrm{HN}}$ & Velocity & $\mathrm{rpm}$ \\
$\mathrm{H}$ & Valve & Main valve in the hot-salt tank & & $\mathrm{SPO}_{\mathrm{H}}$ & Opening & $\%$ \\
$\mathrm{R}$ & Valve & Recirculation valve & & $\mathrm{SPO}_{\mathrm{R}}$ & Opening & $\%$ \\
\hline
\end{tabular}

Table 2. Monitoring elements.

\begin{tabular}{ccccccc}
\hline & Monitoring Element & & \multicolumn{3}{c}{ Output Variable } \\
\cline { 6 - 7 } \cline { 5 - 7 } Element & Description & & Symbol & Magnitude & Unit \\
\hline Thermocouples & Temperature sensors for cold HTF & & $T_{\mathrm{HTFC}}$ & & Temperature & ${ }^{\circ} \mathrm{C}$ \\
Thermocouples & Temperature sensors for hot HTF & & $T_{\mathrm{HTFH}}$ & Temperature & ${ }^{\circ} \mathrm{C}$ \\
Ultrasonic flow meter & Measurement of the flow in cold HTF & & $\dot{m}_{\mathrm{HTF}}$ & Mass flow & $\mathrm{kg} / \mathrm{s}$ \\
Thermocouples & Temperature sensors for cold salt & & $T_{\text {SaltC }}$ & & Temperature & ${ }^{\circ} \mathrm{C}$ \\
Thermocouples & Temperature sensors for hot salt & & $T_{\text {SaltH }}$ & & Temperature & ${ }^{\circ} \mathrm{C}$ \\
Ultrasonic flow meter & Measurement of the flow in cold salt & & $\dot{m}_{\text {Salt }}$ & & Mass flow & $\mathrm{kg} / \mathrm{s}$ \\
\hline
\end{tabular}

Figure 3. Schematic of a thermal solar power plant.

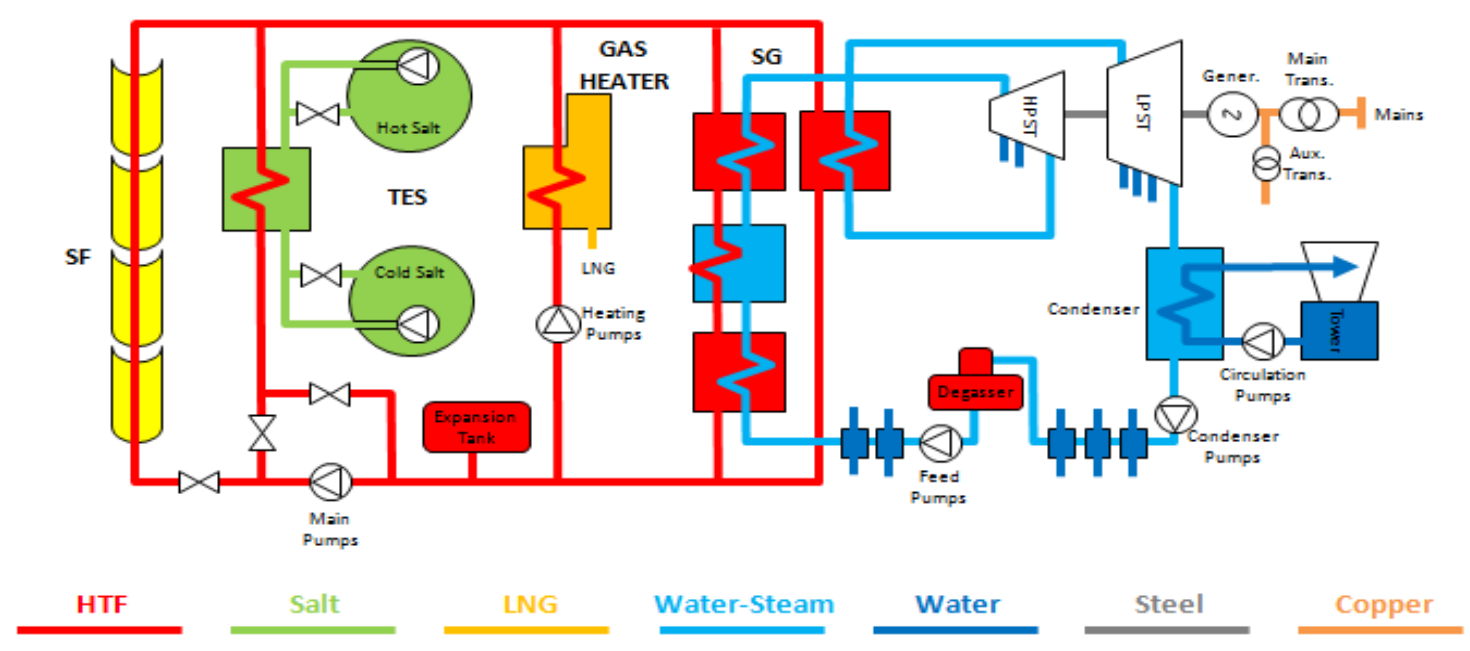

Three main operation modes can be identified in the performance of a TES system: charge, discharge and idle mode. Each of these modes might occur under different conditions as described below.

\subsection{Charging of the TES System}

Charging begins with recirculation of cold salt: it is pumped into the heat exchanger and returned to the tank through valve $R$ (see Figure 1). Then hot HTF passes through the exchanger until the salt is hot enough to be sent to the hot-salt tank; at this moment, the recirculation valve $R$ is closed and the main valve in the hot-salt tank $(H)$ is opened instead.

The mass flow of salt is first controlled by the opening of valve $H$. When this valve has reached its preset opening value, the remaining pumps will be started one by one, thus controlling the flow. Once all the pumps are started, the control is carried out through the frequency converters of the pumps. 
Tables 3-5 include all the variables involved in the process described above are: input variables (used to control the elements included in Table 1), perturbation variables affecting the process and output variables (quantifiable by means of the monitoring elements indicated in Table 2).

Table 3. TES charging input variables.

\begin{tabular}{cl}
\hline & \multicolumn{1}{c}{ Charging of the TES System } \\
\hline Input Variable & \multicolumn{1}{c}{ Description } \\
\hline $\mathrm{SPV}_{\mathrm{Ci}}$ & Set Point for the speed defined by the frequency converter of the $i$-th cold-salt pump \\
$\mathrm{SPO}_{\mathrm{H}}$ & Set Point for the opening of the main valve in the hot-salt tank \\
$\mathrm{SPO}_{\mathrm{R}}$ & Set Point for the opening of the recirculation valve \\
\hline
\end{tabular}

Table 4. TES charging perturbations.

\begin{tabular}{cl}
\hline & \multicolumn{2}{c}{ Charging of the TES System } \\
\hline Perturbation & \multicolumn{1}{c}{ Perturbation } \\
\hline$T_{\mathrm{HTFH}}$ & Hot HTF temperature at the input of the heat exchanger \\
$T_{\mathrm{SalC}}$ & Cold salt temperature at the input of the heat exchanger \\
$\dot{m}_{\mathrm{HTF}}$ & HTF mass flow through the heat exchanger \\
\hline
\end{tabular}

Table 5. TES charging output variables.

\begin{tabular}{cl}
\hline & \multicolumn{1}{c}{ Charging of the TES System } \\
\hline Output Variable & \multicolumn{1}{c}{ Description } \\
\hline$T_{\mathrm{HTFC}}$ & Cold HTF temperature at the output of the heat exchanger \\
$T_{\text {SaltH }}$ & Hot salt temperature at the output of the heat exchanger (control variable) \\
$\dot{m}_{\text {Salt }}$ & Molten salt mass flow through the heat exchanger \\
\hline
\end{tabular}

The goal during this operation mode is regulating temperature $T_{\text {Salt }}$ by adequately setting the values of $\mathrm{SPV}_{\mathrm{Ci}}, \mathrm{SPO}_{\mathrm{H}}$ and $\mathrm{SPO}_{\mathrm{R}}$ while taking perturbations into account and having the other output variables provide insight into what is actually happening. The model to develop must make all these variables available. Figure 4 shows a block representation of the charging process.

Figure 4. Process block associated to TES charging.

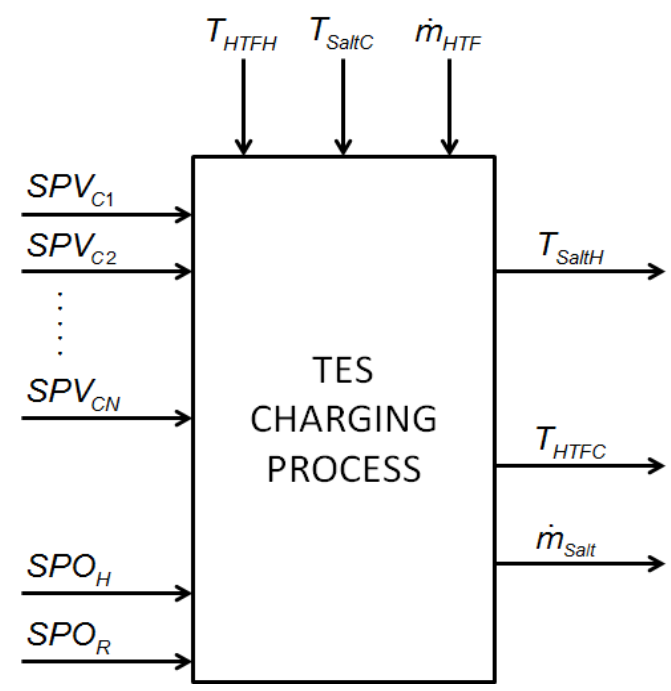


It must be noticed that, depending on whether it is the solar field (SF) or the gas heater that supplies the thermal energy storage (TES) system (and perhaps the steam generator system, SGS, as well), charging of the thermal energy storage system can take place in either of the following ways.

\subsubsection{From SF to SGS + TES}

In some summer days, around noon, the thermal energy produced by the solar field (SF) is greater than that required to operate the turbine at nominal power. This excess of energy must be stored in the molten salt while the steam generation system (SGS) keeps operating at nominal power.

\subsubsection{From SF to TES}

In winter days, when the thermal power provided by the solar field is not enough to operate the turbine with an acceptable efficiency, the choice is storing all of this energy in the molten salt.

\subsubsection{From Gas Heater to TES}

When the molten salt needs to be heated but there is not enough energy coming from the solar field, the gas heater can be used for this purpose.

The difficulty associated to the control of each of these charging processes varies according to the variations of HTF mass flow and temperature during the charge.

\subsection{Discharging of the TES System}

Discharge begins by pumping hot salt through the heat exchanger and into the cold-salt tank through its main valve $(C)$. Then cold HTF passes through the exchanger to be heated. As HTF flow increases, salt flow is increased too by opening valve $C$. When this valve has reached its preset opening value, the remaining pumps will be started one by one, thus controlling the flow. Once all the pumps are started, the control is carried out through the frequency converters of the pumps.

The variables involved in the process described above are summarized in Tables 6 to 8 :

Table 6. TES discharging input variables.

\begin{tabular}{cc}
\hline & \multicolumn{1}{c}{ Discharging of the TES System } \\
\hline Input Var. & \multicolumn{1}{c}{ Description } \\
\hline $\mathrm{SPV}_{\mathrm{Hi}}$ & Set Point for the speed defined by the frequency converter of the $i$-th hot-salt pump \\
$\mathrm{SPO}_{\mathrm{C}}$ & Set Point for the opening of the main valve in the cold-salt tank \\
\hline
\end{tabular}

Table 7. TES discharging perturbations.

\begin{tabular}{cl}
\hline & \multicolumn{1}{c}{ Discharging of the TES System } \\
\hline Perturbation & \multicolumn{1}{c}{ Description } \\
\hline $\mathrm{T}_{\mathrm{HTFC}}$ & Cold HTF temperature at the input of the heat exchanger \\
$\mathrm{T}_{\text {SaltH }}$ & Hot salt temperature at the input of the heat exchanger \\
$\dot{m}_{\mathrm{HTF}}$ & HTF mass flow through the heat exchanger \\
\hline
\end{tabular}


Table 8. TES discharging output variables.

\begin{tabular}{cc}
\hline & \multicolumn{2}{c}{ Discharging of the TES System } \\
\hline Output Var. & \multicolumn{1}{c}{ Description } \\
\hline$T_{\mathrm{HTFH}}$ & Hot HTF temperature at the output of the heat exchanger (control variable) \\
$T_{\text {SaltC }}$ & Cold salt temperature at the output of the heat exchanger \\
$\dot{m}_{\text {Salt }}$ & Molten salt mass flow through the heat exchanger \\
\hline
\end{tabular}

The goal in this case is regulating temperature $T_{\mathrm{HTFH}}$ by adequately setting the values of SPV $\mathrm{Hi}_{\mathrm{H}}$ and SPOC $_{C}$ while taking perturbations into account and having the other output variables provide insight into what is actually happening. A possible block representation of the discharging process that presents all the variables described above is shown in Figure 5.

Figure 5. Process block associated to TES discharging.

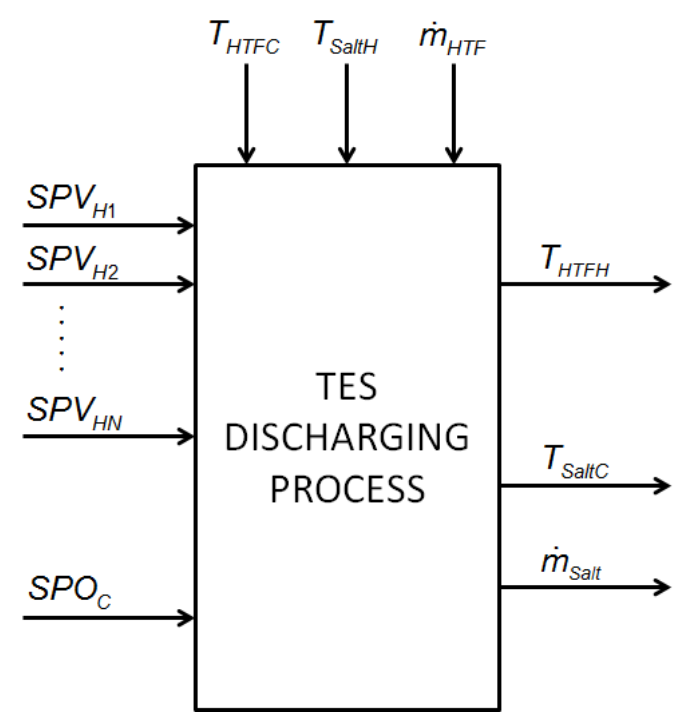

Similarly to the charging process, discharging the thermal energy storage system can also take place in either of the following ways.

\subsubsection{From SF + TES to SGS}

The energy provided by the solar field is not enough to have the steam generation system provide the power required. The thermal energy storage system supplies additional energy to make the SGS operate as close as possible to nominal power conditions.

\subsubsection{From TES to SGS}

All the energy provided by the generator comes from the TES (typical situation at nights). The power obtained is slightly lower than nominal power.

\subsubsection{From TES + Gas Heater to SGS.}

Sometimes the TES system cannot provide enough energy to operate the steam generation system at the required power. In these cases, the gas heater can be used to supply additional energy. 
Regulation of both the charge and discharge processes experiences several problems, namely: process perturbations, measurement errors and non-linearity. As already stated, optimization of all these processes cannot be carried out unless an accurate model of the process is available.

\subsection{TES System in Idle Mode}

This mode corresponds to the idle times between charge and discharge. No regulation is required during this mode.

After the TES system has been fully charged, it enters idle mode, with the hot-salt tank full, until the SF cannot keep the turbine operating at nominal power.

After the TES has been completely discharged, it enters idle mode, with the hot-salt tank empty, until the SF provides an excess of thermal power above that required by the turbines (typically the following day).

\section{Model Definition}

Up to this point, two models have been described: one for the charge and another for the discharge of the TES system. It might be argued that having two process models is not functional since the system is the same in both cases. Despite this being true, the fact that internal flows are opposite during charge and discharge, and that relevant input/output variables change for each case, has led authors to consider it more convenient to have two separate models. In addition, charge and discharge are completely independent process (either the TES system is charging or it is discharging) and can therefore be optimized separately.

Whatever the model considered (charge or discharge), only three basic equations are needed to define the performance of a thermal energy storage system: mass conservation, energy conservation and heat transmission. Other than that, the models must accurately define the mass flows within the system.

The rest of the paper focuses on the description of a model associated to the charge process of a TES to be included in a simulation oriented visual environment. Although Matlab-Simulink blocks are shown, any other simulation environment of these characteristics could be used. The model will be developed by carrying out a top-down partitioning of the system in order to have it implemented bottom-up later. The model associated to the discharge can be similarly obtained.

Figure 6 shows the simplified model associated to the charge process in the TES system. As can be seen, the set points of the valves are not directly provided in actual systems. Instead, there is a simple internal PID regulator that implements mass-flow control through the frequency converters of the pumps. This is represented in the figure and considered to be part of the model to be derived.

From this point on, the aforementioned top-down analysis is carried out so that the subsystems included in each block are defined. To start with, the TES charge process is modeled by the pumps controlling the mass flow entering the trains of exchangers as indicated in Figure 7. The TES discharge model will only differ from this in the input and output variables (refer to Figure 5 to see these variables). 
Figure 6. Simulink model for TES charge simulations.

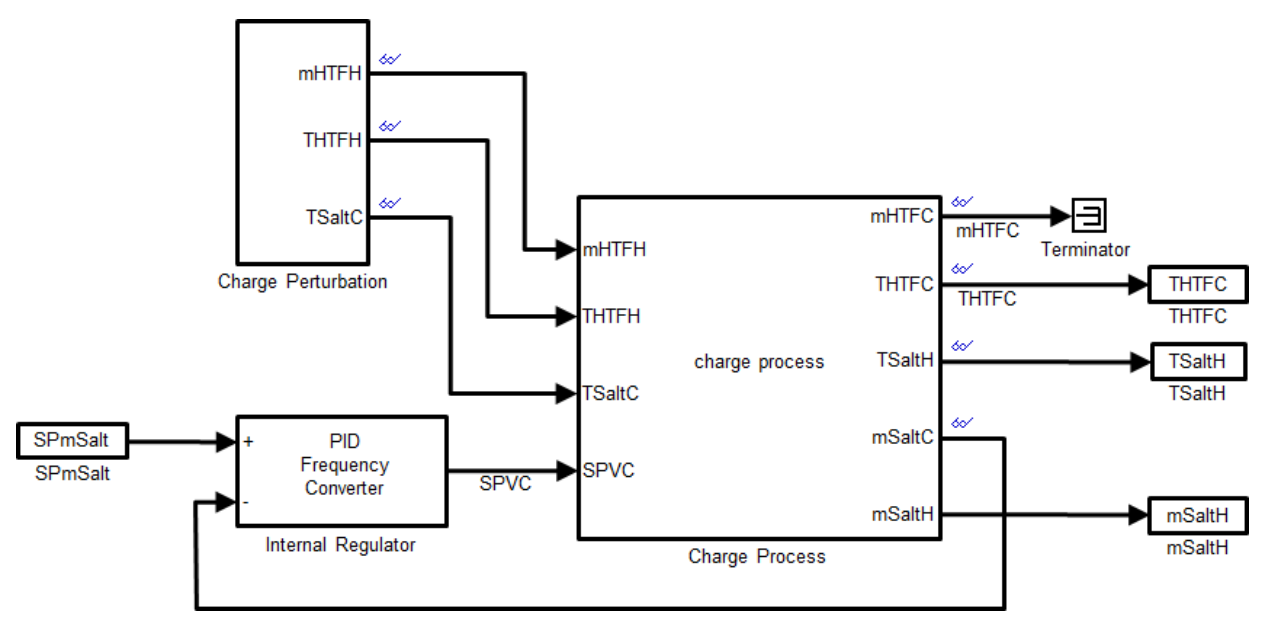

Figure 7. Diagram for TES charge process.

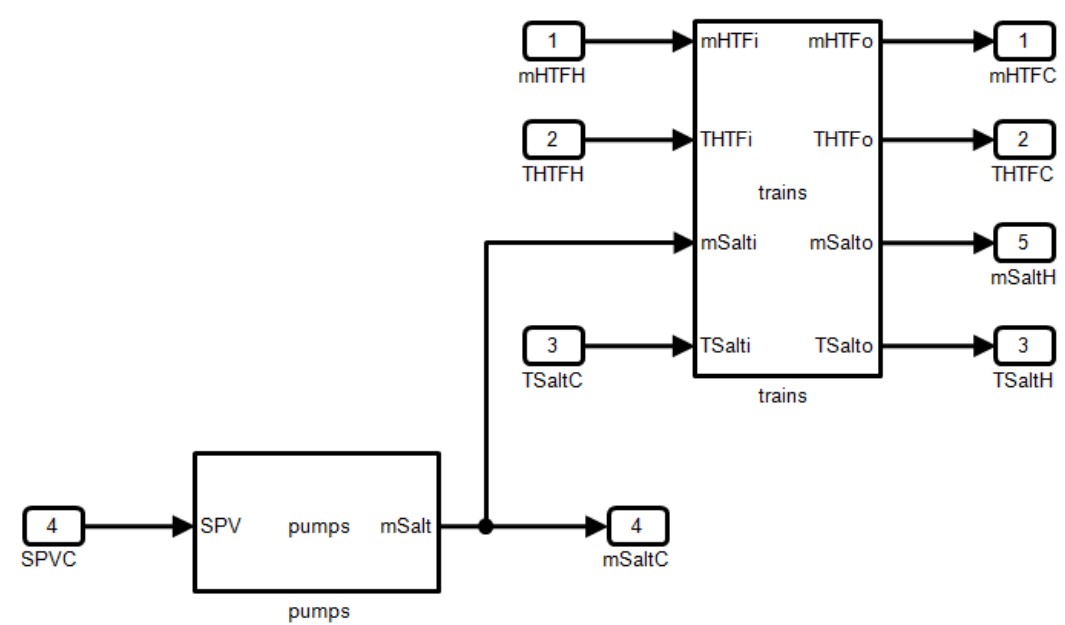

The main block in this TES charge model is the trains block. This block is meant to define the performance of the HTF-Salt heat exchanger, which may consist of several series-connected modules. In the case considered for this work, a system with several trains connected in parallel has been defined. In turn, each of these trains includes several heat exchangers connected in series. The trains block must accurately model all the different parts in a heat exchanger and their relations. Accurate description of the flows inside the system is needed in order to obtain a valid model. Figure 8 shows these parts.

Figure 8. Components of an HTF-Salt heat exchanger.

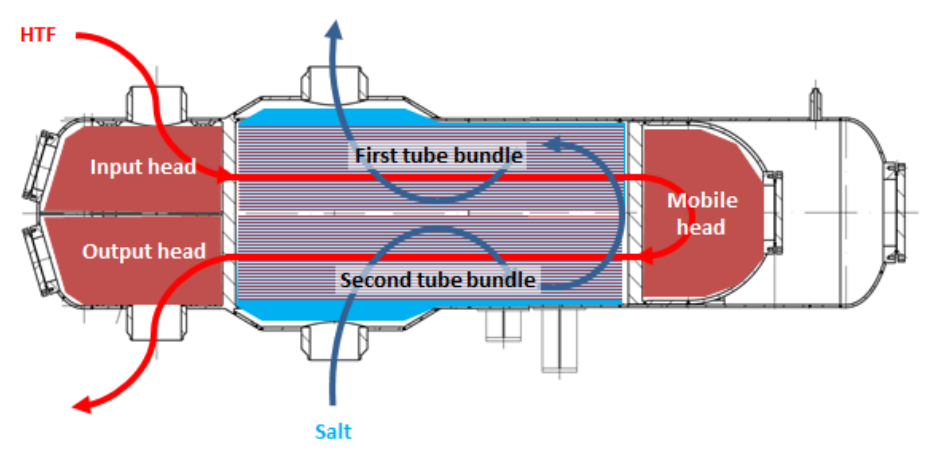


Shell-and-tube heat exchangers are very common in process industry and their transient modeling has been subject of numerous publications [33-35]. Accurate modeling of this kind of devices involves considering the shell-side convective heat transfer over the tube bundle in detail. This is typically done via the Bell-Delaware method [36-38], which is an empirical method based on numerous experiments with shell-and-tube heat exchangers. Recently, there have also been published some numerical studies that reconfirmed its validity [39-41].

However, the model of the thermal energy storage system does not require a very accurate heat-exchanger model to adequately define the heat transfer. The heat exchanger model should accurately represent the dynamic effects that provide the TES model with a good estimation of the time-evolution of the system operations. Different heat transfer models for the heat-exchangers have been tried by the authors with negligible impact on the simulation results, and with complex heat transfer models increasing the computational time due to the complexity of the overall model. In addition, 2-D or 3-D models have been tried for the heat exchangers sections or volumes, with negligible impact on the simulation results. In fact, experience has shown that, rather than a high accuracy in temperature values, it is necessary to have a system that adequately models the delays produced in very large heat exchangers like the ones used in these power plants. It must be taken into account that these heat exchangers might consist of up to six trains connected in series (as is the case in Andasol I, a 150-MW thermal power plant in Andalusia, southern Spain), which results in relatively long delays before the response is obtained at the output. Should these delays not be properly modeled, the parameters of the PID regulator that controls the overall system cannot be adequately calculated, thus giving rise to abnormal operation.

Thus, a simple 1-D model has been used to define the heat exchanger. The flux exchange is considered to be unidirectional and the bundles are divided into smaller discrete parts where the basic heat transfer equations will be solved. No 3-D simulation of the shell is deemed necessary.

The interface variables for the heat exchanger are shown in Tables 9 and 10.

Table 9. Heat exchanger input variables.

\begin{tabular}{cc}
\hline & Heat Exchanger \\
\hline Input Var. & Description \\
\hline$\dot{m}_{\mathrm{HTFi}}$ & Input HTF mass flow \\
$\mathrm{T}_{\mathrm{HTFi}}$ & Input HTF temperature \\
$\mathrm{T}_{\mathrm{HTFc}}$ & Counterflow input HTF temperature \\
$\dot{m}_{\mathrm{Salti}}$ & Input salt mass flow \\
$\mathrm{T}_{\text {Salti }}$ & Input salt temperature \\
$\mathrm{T}_{\text {Saltc }}$ & Counterflow input salt temperature \\
\hline
\end{tabular}

Table 10. Heat exchanger output variables.

\begin{tabular}{cc}
\hline \multicolumn{2}{c}{ Discharging of the TES System } \\
\hline Output Var. & Description \\
\hline$\dot{m}_{\text {HTFo }}$ & Output HTF mass flow \\
$\mathrm{T}_{\text {HTFo }}$ & Output HTF temperature \\
$\dot{m}_{\text {Salto }}$ & Output salt mass flow \\
$\mathrm{T}_{\text {Salto }}$ & Output salt temperature \\
\hline
\end{tabular}


Figure 9 shows the block diagram for the exchanger depicted in Figure 8. The connection between the different blocks (input head, first bundle, mobile head or turn, second bundle and output head) represents actual flow inside the exchanger (assuming a one-dimensional simplification), thus contributing to obtaining an accurate model of the overall process.

Figure 9. Diagram for the heat exchanger.

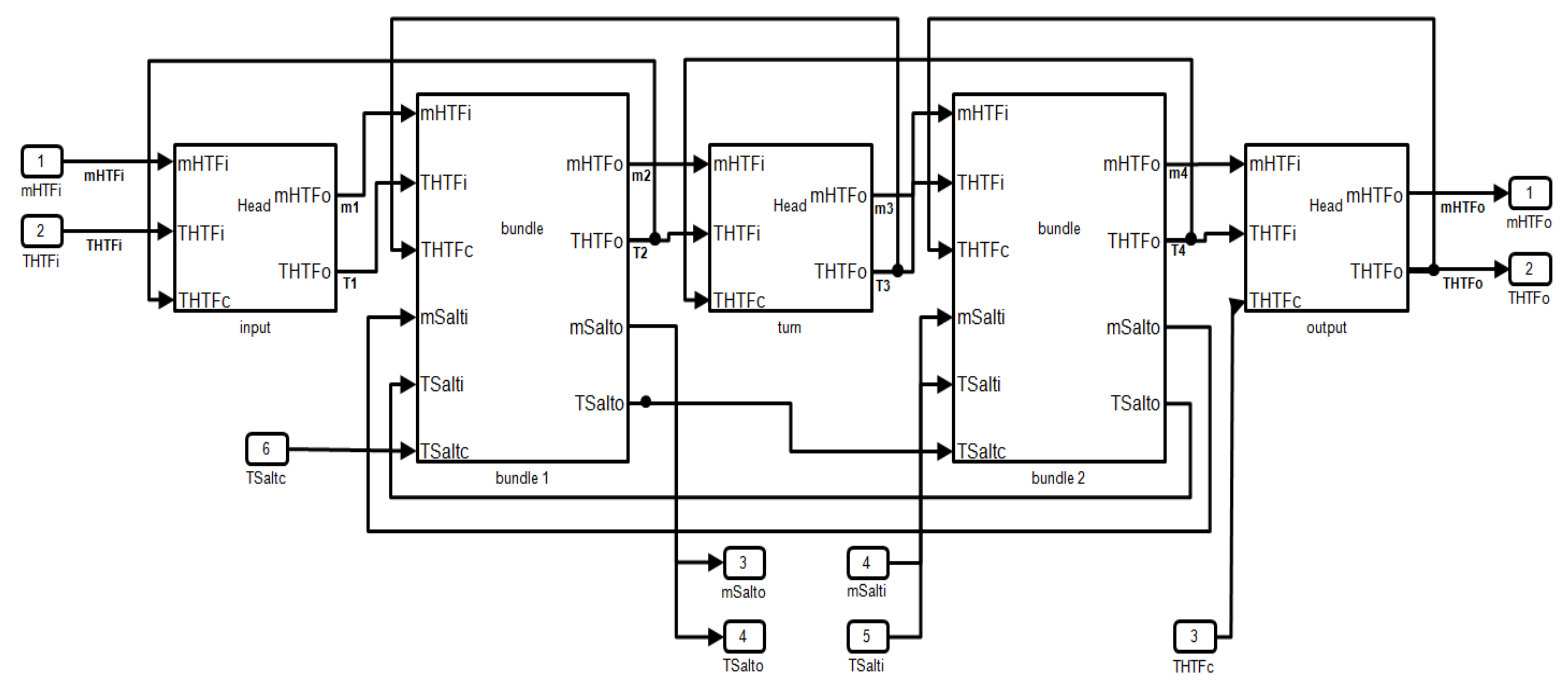

Similarly, the bundle blocks must include information of how many tubes form part of the bundle and how the HTF flows through them. This can be achieved by defining block "tube" and using several of them adequately connected to define the block "bundle". The number of tubes and the connections between them depends on the actual exchanger being considered: there will be a different and unique model for each type of exchanger.

It is inside the exchanger that energy transfer between the fluids is carried out. In order to model this phenomenon equation blocks must be included both in the bundle model and in the head model. Both these models implement equations related to mass conservation, Equation (1), and energy conservation, Equation (2), in order to derive output mass flows and output temperatures:

$$
\begin{gathered}
\frac{d M}{d t}=-\oiint \rho \cdot \vec{v} \cdot \overrightarrow{d S} \\
\frac{d E}{d t}=-\oiint \rho \cdot\left(h+\frac{v^{2}}{2}+g \cdot z\right) \cdot \vec{v} \cdot \overrightarrow{d S}-\dot{Q}
\end{gathered}
$$

These equations can be simplified considering actual constraints of the process within the control volume considered, such as constant density, incompressible flow, similar input and output mass flows or negligible potential and kinetic energy. Under these considerations, the mass conservation equation to be implemented is:

$$
\dot{m}_{o}=\dot{m}_{l}-V \cdot \frac{d \rho_{F L U I D}(T)}{d t}
$$

where $\dot{m}_{i}$ and $\dot{m}_{o}$ are the input and output mass flows, $V$ is the control volume considered and $\rho$ FLUID is the fluid density. 
As far as the energy conservation equation is concerned, the assumptions above result in an enthalpy equation, which is the one to be implemented in the model:

$$
\frac{d H}{d t}=-\oiint \rho \cdot h \cdot \vec{v} \cdot \overrightarrow{d S}-\dot{Q}
$$

where $\rho$ is the fluid density, h is the fluid enthalpy, $v$ is the fluid velocity, $S$ is the external surface of the control volume and $\dot{Q}$ is the heat transmission out of the control volume.

Additionally, the model of the bundle, implements Equation (5) in order to derive the heat transmission between the control volume of the HTF and that of the molten salt through the steel tubes:

$$
\dot{Q}=U \cdot A \cdot\left(\overline{T_{\text {HTF }}}-\overline{T_{\text {Salt }}}\right)
$$

where $U$ is the global heat transmission coefficient, A is the exchange area and the temperatures used are average values corresponding to HTF and salt; average values are used instead of logarithmic values to avoid problems derived from the fact that it is possible to have the temperature difference inverted during transients. The global heat transmission coefficient, $U$, included in this equation considers thermal conductivity of the steel and of the fluids involved in the heat exchange as well as superficial heat transmission both inside and outside of the bundles:

$$
U=\frac{1}{\frac{D_{e}}{D_{i} \cdot h_{i}}+\frac{D_{e} \cdot \ln \left(D_{e} / D_{i}\right)}{2 \cdot k_{S T E E L}}+\frac{1}{h_{e}}}
$$

where $D_{\mathrm{i}}$ is the tube internal diameter, $D_{\mathrm{e}}$ is the tube external diameter, $k$ sTEEL is the steel thermal conductivity, $h_{\mathrm{i}}$ is the film coefficient inside the tube and $h_{\mathrm{e}}$ is the film coefficient outside the tube.

The parameters associated to superficial heat transmission inside the tubes $\left(h_{i}\right)$ are all related to the HTF (Nusselt number, Reynolds number, Prandtl number, fluid speed, flow, viscosity). The Nusselt number for the HTF inside a round tube can be calculated as:

$$
N u_{H T F}=0.023 \cdot R e_{H T F}^{0.8} \cdot \operatorname{Pr}_{H T F}{ }^{n}
$$

where $n$ equals 0.33 when salt is being charged, and 0.4 when it is being discharged; the other parameters (Reynolds and Prandtl numbers) depend on the type of HTF used.

The same parameters related to the molten salt are used to determine heat transmission on the external surface of the tubes $\left(h_{\mathrm{e}}\right)$. In this case, and taking into account the one-dimensional assumption indicated above [42], the Nusselt number for the salt going through the bundle of tubes is calculated to be:

$$
N u_{\text {Salt }}=0.41 \cdot R e_{\text {Salt }}^{0.6} \cdot P r_{\text {Salt }}^{1 / 3} \cdot\left(\frac{P r_{\text {Salt }}}{P r_{\text {Salt }}}\right)^{1 / 4} \cdot \varphi_{1}
$$

where $\varphi_{1}$ equals 1.12 as corresponds to a situation in which the tube to tube pitch normal to flow is longer than twice the tube to tube pitch parallel to flow; the other parameters in Equation (8) are the Reynolds number of the salt, Resalt, the Prandtl number of the salt, $P r_{\text {Salt }}$, and the Prandtl number of the salt on the outer surface of the tubes, $\operatorname{Pr}$ salto.

By adequately combining the above-defined blocks, it is possible to model any complete TES charge process. The blocks defined have been kept simple so that it is easy to determine how to link one to another. The fact that they represent actual physical phenomena or system disposition also contributes to simplifying the task of adapting them to model a given process. A dynamic model like 
the one presented here is necessary in order to optimize the TES process as a whole, especially its regulation. Nowadays, the control of this process is performed by means of simple, non-optimized control methods. The model presented in this paper might contribute to improving the state of the art by allowing advanced control techniques to be tested so that more convenient algorithms can be implemented in this part of the power plant and, hence, improve the overall performance of the plant.

\section{Model Validation}

Validation of the model presented was carried out in two stages. Firstly, simple simulations were run in order to find out whether the results obtained were consistent with the behavior expected. Secondly, the information provided by the model was compared to that measured in an actual plant.

Two simulations were run considering the two most usual control strategies to regulate this kind of processes: a so-called semiautomatic control and a PID regulator. These control methods are very popular and widely used for TES regulation. Since they are well-known strategies, they will be used together with the model developed in order to validate its performance. The main features of these control methods are sketched below.

In the case of semiautomatic control, an operator is in charge of observing the values of the output variables and defining new set points for the input variables. Thus, the regulation will be carried out by means of steps, the accuracy of which depends only on the operator's experience. For a charge process, this person will define the set point for the salt mass flow (SP $\left.\dot{m}_{\text {Salt }}\right)$ while observing the evolution of the output salt temperature $\left(T_{\text {Salt }}\right)$. Internal PID regulators will be in charge of operating the pumps so that the set point fixed by the operator is achieved. Figure 10 shows a block diagram of the whole system.

Figure 10. Semiautomatic control of a TES charge process.

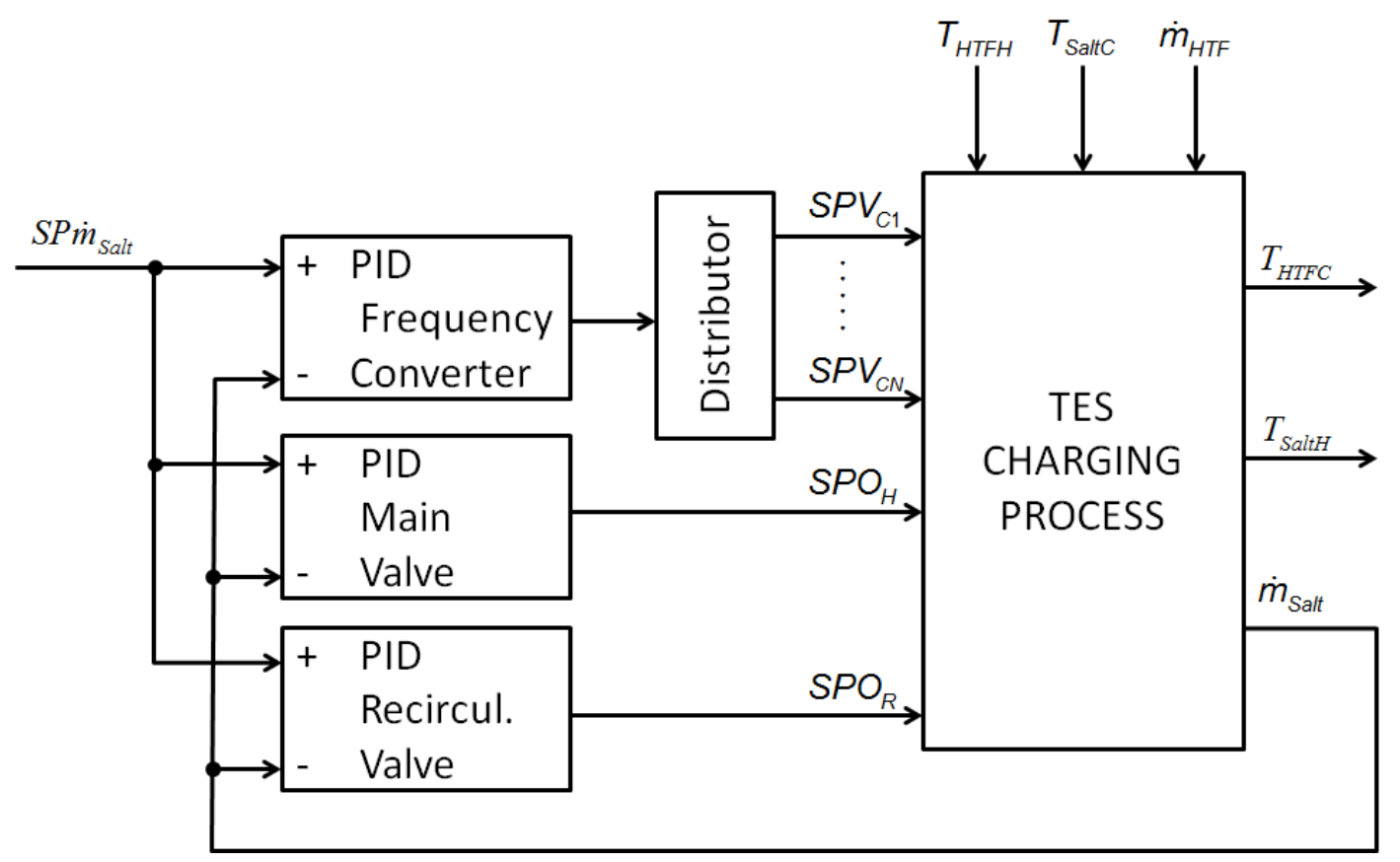

In a PID control, the person in charge is substituted by an external regulation loop. A simple PID regulator is usually enough in these cases, and only the set point for the desired output salt temperature must be provided. This system is depicted in Figure 11. 
Figure 11. PID regulator in a TES charge process.

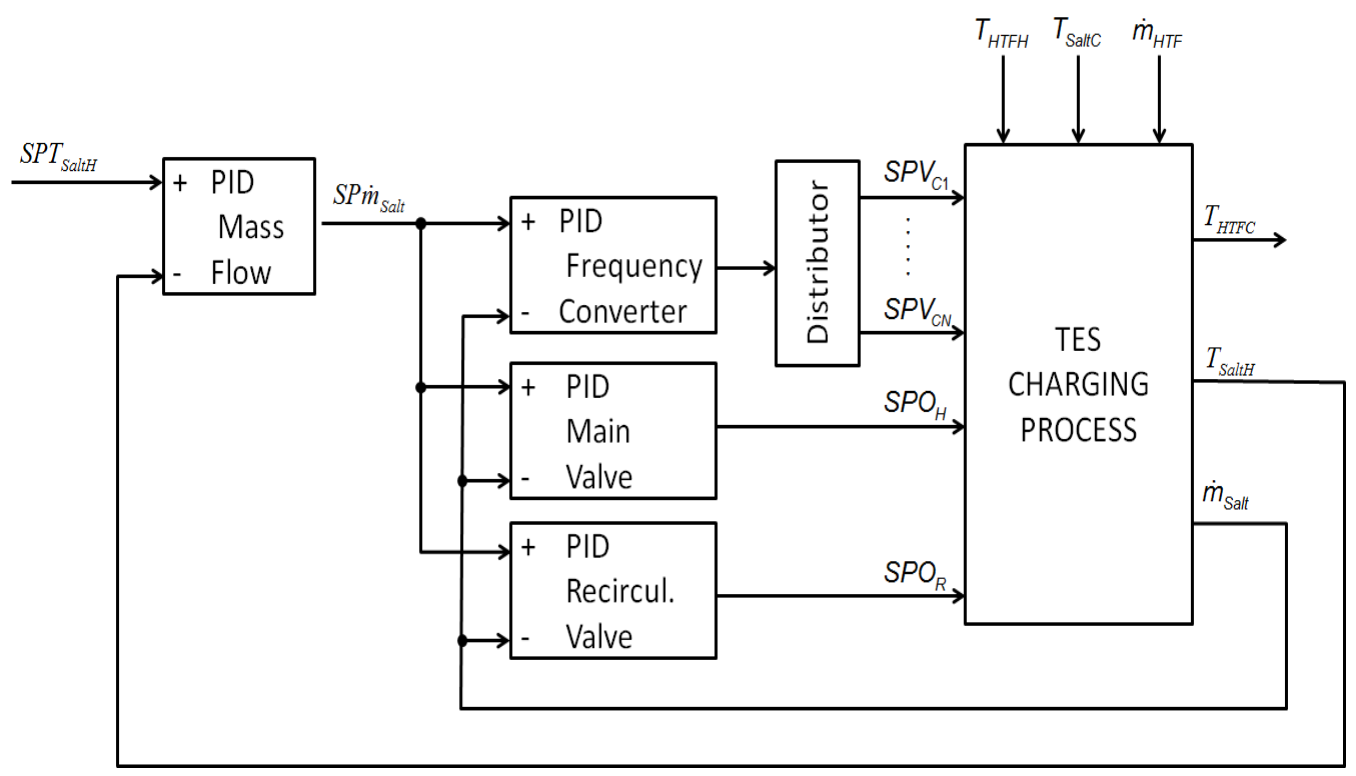

A complete TES model implemented with MatLab-Simulink was used to determine whether the results obtained matched the expected ones. The performance of the system during a period of five hours was simulated considering a semiautomatic control and a PID control.

Figure 12 shows a representative $3000 \mathrm{~s}$ sample of the evolution of the error made in the hot salt temperature ( $\left.e T_{\mathrm{SaltH}}\right)$ when simulating the performance of the model together with the control strategies described above; this error is defined as the difference between the temperature obtained and the set point established $\left(\mathrm{SPT}_{\text {SaltH }}=384.5^{\circ} \mathrm{C}\right): e T_{\text {SaltH }}=T_{\text {SaltH }}-$ SPT $_{\text {SaltH }}$. Variations of the perturbations in the system, $T_{\mathrm{HTFH}}$ and $\dot{\mathrm{m}}_{\mathrm{HTF}}$ (the cold salt temperature was considered to have a constant value $T_{\text {SaltC }}=298^{\circ} \mathrm{C}$ ) during the time interval considered are represented in Figure 13 . These perturbations are actual values measured in a real power plant and applied to the model developed. The variations shown are related to the regulator not being ideal (in the case of $T_{\mathrm{HTFH}}$, although a $\pm 2{ }^{\circ} \mathrm{C}$ variation can be considered to be a very good result) or to solar insolation conditions (which affect the value of $\dot{\mathrm{m}}_{\mathrm{HTF}}$ ).

Figure 12. Simulation of the hot salt temperature error obtained during the charge process.

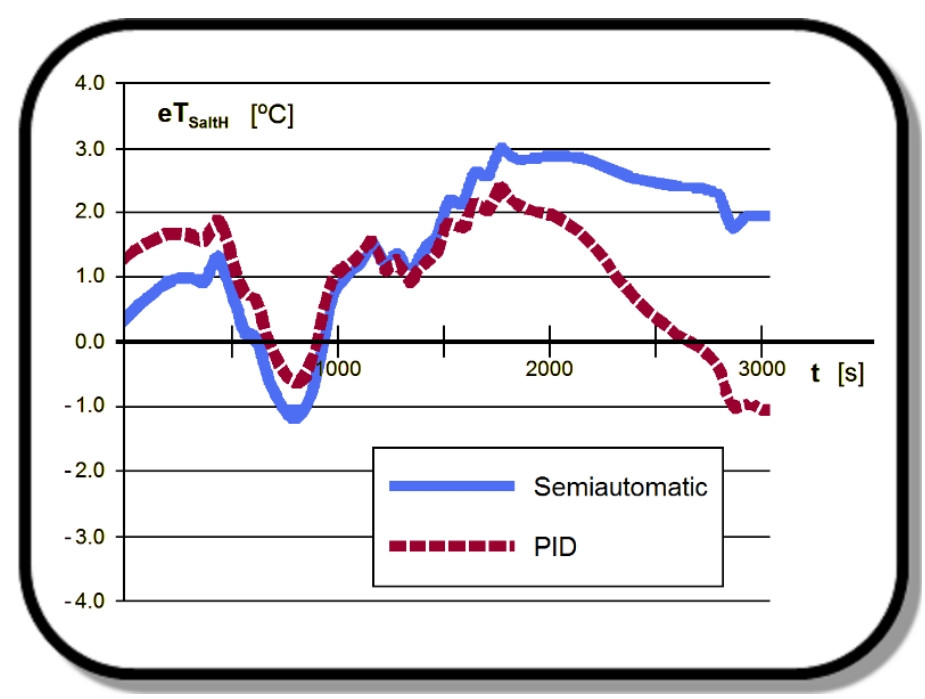


Figure 13. Variation of the perturbations considered when calculating the error represented in Figure 12.
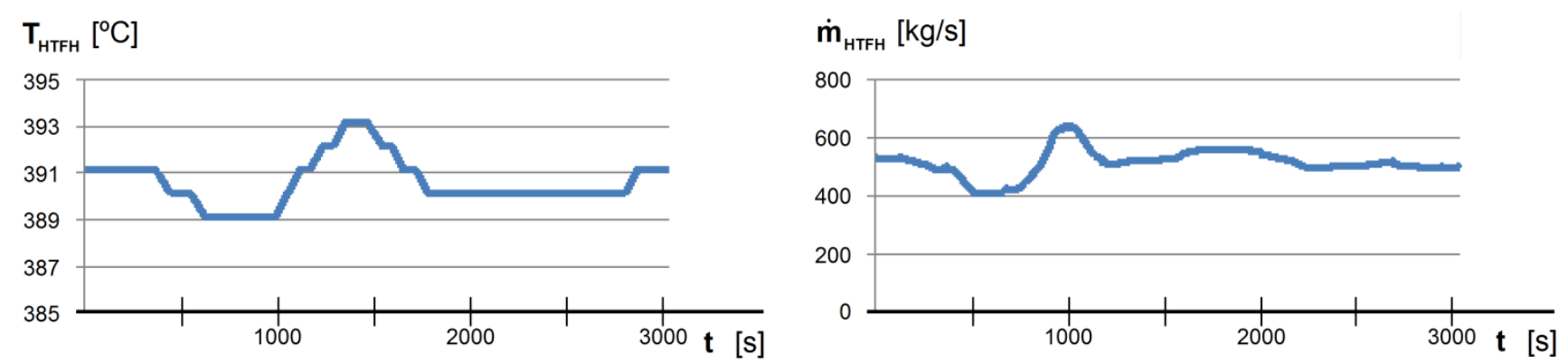

The results obtained in the simulations seem to indicate that the hot salt temperatures calculated by the model follow the set points established. As was to be expected, the accuracy obtained with PID regulation is higher than that obtained with the semiautomatic control, which validates the performance of the model.

For the sake of convenience, only a small fraction of the simulation has been represented, but the accuracy mentioned above can also be seen in Table 11, where $\mu$ represents the error average value and $\sigma$ is the error standard deviation calculated for the whole set of data obtained during the five hours; as already indicated, the variations of the perturbations considered throughout the simulation are actual values measured in a real plant. As was to be expected, both values are lower when using a PID regulator.

Table 11. Numerical results of the simulation test.

\begin{tabular}{|c|c|c|c|}
\hline \multirow{2}{*}{ Control Strategy } & \multicolumn{3}{|c|}{$e T_{\text {SaltH }}=T_{\text {SaltH }}-S P T_{\text {SaltH }}$} \\
\hline & $\mu$ & $\sigma$ & Confidence Interval \\
\hline Semiautomatic control & 0.72 & 1.74 & {$[-2.76,4.20]$} \\
\hline PID regulator & 0.38 & 1.17 & {$[-1.96,2.72]$} \\
\hline
\end{tabular}

Once simulation results have validated the performance of the model, further tests were carried out using actual measurements from a real thermal power plant in order to compare them with the results provided by the model. The plant chosen was "SAMCA2-La Dehesa", a 50-MW PTC thermal plant built by Group TSK in 2010, with a TES capacity of $7 \mathrm{~h}$. The comparison was established by considering the net energy generated by the thermal plant during a discharge of the TES. Using the set of actual data collected in the plant (and further measurements taken when necessary), the model developed was supplied with the information of the actual values used for the input variables. The outputs provided by the model under these conditions were compared to those stored in the thermal plant. Table 12 shows how both results (actual and simulated) compare when used to determine the net energy produced after seventeen complete discharges. Results are provided for every hour of the discharge process, which always takes place during the night, when the solar field is not providing energy to the plant. Production for the 17 discharges is added for every hour in Table 12. 
Table 12. Comparison of the net energy produced after 17 discharges.

\begin{tabular}{|c|c|c|c|c|c|c|}
\hline \multirow{3}{*}{$\begin{array}{c}\text { Time Interval } \\
\text { Considered }\end{array}$} & \multicolumn{6}{|c|}{ Net Energy $(M W \cdot h)$} \\
\hline & \multicolumn{3}{|c|}{ Semiautomatic Control } & \multicolumn{3}{|c|}{ PID Regulator } \\
\hline & $\begin{array}{c}\text { Real } \\
\left(E_{\mathrm{N}, \text { Real }}\right)\end{array}$ & $\begin{array}{c}\text { Simulated } \\
\left(E_{\mathrm{N}, \text { Simulated }}\right)\end{array}$ & $\begin{array}{c}\text { Difference } \\
(\%)\end{array}$ & $\begin{array}{c}\text { Real } \\
\left(E_{\mathrm{N}, \text { Real }}\right)\end{array}$ & $\begin{array}{c}\text { Simulated } \\
\left(E_{\mathrm{N}, \text { Simulated }}\right)\end{array}$ & $\begin{array}{c}\text { Difference } \\
(\%)\end{array}$ \\
\hline $23 \mathrm{~h}-00 \mathrm{~h}$ & 1435 & 1432 & $+0.2 \%$ & 1453 & 1450 & $+0.2 \%$ \\
\hline 00 h-01 h & 1363 & 1368 & $-0.3 \%$ & 1381 & 1377 & $+0.3 \%$ \\
\hline $01 \mathrm{~h}-02 \mathrm{~h}$ & 1148 & 1148 & $0.0 \%$ & 1163 & 1166 & $-0.3 \%$ \\
\hline $02 \mathrm{~h}-03 \mathrm{~h}$ & 789 & 786 & $+0.5 \%$ & 799 & 801 & $-0.2 \%$ \\
\hline 03 h-04 h & 431 & 434 & $-0.8 \%$ & 436 & 437 & $-0.2 \%$ \\
\hline $04 h-05 h$ & 215 & 217 & $-1.0 \%$ & 218 & 217 & $+0.7 \%$ \\
\hline $05 \mathrm{~h}-06 \mathrm{~h}$ & 72 & 74 & $-3.0 \%$ & 73 & 71 & $+2.0 \%$ \\
\hline Total & 5453 & 5459 & $-0.1 \%$ & 5522 & 5518 & $+0.1 \%$ \\
\hline
\end{tabular}

Since each of these tests lasted one day and only one of the control strategies could be analyzed at a time, the experiments were conducted according to the following criteria:

- The tests should not interfere with current production.

- All the tests were performed during the summer in order to have similar radiation conditions.

- Pairs or consecutive days, one for each of the control strategies, were chosen for the analysis so that both of them would take place under as similar conditions as possible.

- The real net energy produced in the plant was measured before and after the discharge, and then compared with that calculated by using the model.

The results obtained further confirm that the model described in this paper accurately represents the behavior of thermal energy storage systems in solar power plants. Nevertheless, it must be pointed out that the model presented in this paper is not actually meant to estimate the energy produced in the solar plant. The main use of this model is designing the regulation of the thermal storage system; Table 12 has only been used as a way to validate the accuracy of the results provided by this model.

\section{Conclusions}

A simulation dynamic model of the molten-salt thermal energy storage system included in thermal power plants has been developed. The model has been described to be used in simulation oriented visual environments, so that physical aspects or component disposition in the system to be modeled can be easily described.

This model accurately determines delays in the system that must be taken into account when designing the control strategy associated to the heat storage system. This is especially important when large heat exchangers consisting of several trains connected in series are included in the thermal solar power plant.

The precision of the model has been validated by simulation and by comparison with actual data obtained from a real PTC thermal plant. In both cases, the results obtained proved the accuracy of the response offered by the model developed.

The availability of the TES model described in this paper opens new possibilities in optimization of the charge/discharge process of heat storage systems and, hence, improvement of the overall efficiency of the solar thermal plant. 


\section{Author Contributions}

This paper is part of the $\mathrm{PhD}$ Thesis developed by Rogelio Peón Menéndez, who has therefore carried out most of the work presented here. Professors Juan Á. Martínez and Miguel J. Prieto were the supervisors of this work, whereas Lourdes Á. Barcia and Juan M. Martín Sánchez respectively assisted Rogelio Peón with Simulink simulations and regulation topics.

\section{Conflicts of Interest}

The authors declare no conflict of interest.

\section{References}

1. Yang, Z.; Garimella, S.V. Cyclic operation of molten-salt thermal energy storage in thermoclines for solar power plants. Appl. Energy 2013, 103, 256-265.

2. Usaola, J. Operation of concentrating solar power plants with storage in spot electricity markets. IET Renew. Power Gener. 2012, 6, 59-66.

3. Weinrabe, G.; Ortmanns, W. Solar thermal power plants. In Renewable Energy; Kaltschmitt, M., Streicher, W., Wiese, A., Eds.; Springer: Berlin, Germany, 2007; pp. 171-228.

4. Schnatbaum, L. Solar thermal power plants. Eur. Phys. J. Spec. Top. 2009, 176, 127-140.

5. Wu, S.Y.; Xiao, L.; Cao, Y.; Li, Y.R. A parabolic dish/AMTEC solar thermal power system and its performance evaluation. Appl. Energy 2010, 87, 452-462.

6. Ter-Gazarian, A.G. Thermal Energy Storage. In Energy Storage for Power Systems; IET Press: Stevenage, UK, 2011; pp. 55-76.

7. Sangster, A.J. Intermittency buffers. In Green Energy and Technology. Energy for a Warming World; Sangster, A.J., Ed.; Springer: Berlin, Germany, 2010; pp. 81-123.

8. Steinmann, W.D.; Laing, D.; Tamme, R. Storage systems for solar steam. In Proceedings of ISES World Congress 2007 (Vol. I - Vol. V); Springer: Berlin, Germany, 2007; pp. 2736-2740.

9. Laing, D.; Steinmann, W.D.; Tamme, R. Sensible heat storage for medium and high temperatures. In Proceedings of ISES World Congress 2007 (Vol. I - Vol. V); Springer: Berlin, Germany, 2007; pp. 2731-2735.

10. Goods, S.H.; Bradshaw, R.W. Corrosion of stainless steels and carbon steel by molten mixtures of commercial nitrate salts. J. Mater. Eng. Perform. 2004, 13, 78-87.

11. USA Trough Initiative. Thermal Storage Oil-to-Salt Heat Exchanger Design and Safety Analysis; Task Order Au. No. KAF-9-29765-09; Nexant Inc.: San Francisco, CA, USA, 2000.

12. Annaratone, D. Engineering Heat Transfer; Springer: Berlin, Germany, 2010.

13. Massoud, M. Engineering Thermofluids; Springer: Berlin, Germany, 2005.

14. Damsker, D.J.; Sandberg, C. Towards advanced concurrency, distribution, integration, and openness of a power plant distributed control system (DCS). IEEE Trans. Energy Convers. 1991, 6, 297-302.

15. Bong-Kuk, L.; Yong-Hak, S. The integrated monitoring and control system for the combined cycle power plant. In Proceedings of the International Conference on Control, Automation and Systems, Seoul, Korea, 14-17 October 2008; pp. 1479-1483. 
16. Rajasekaran, S. A Simplified predictive control for a shell and tube heat exchanger. Int. J. Eng. Sci. 2010, 2, 7245-7251.

17. Garcia, C.E.; Prett, D.M. Model predictive control: Theory and practice-A survey. Automatica 1989, 25, 335-348.

18. Lim, K.W.; Ling, K.V. Generalized predictive control of a heat exchanger. IEEE Control Syst. Mag. 1989, 1, 9-12.

19. Nelles, O. Nonlinear System Identification: From Classical Approaches to Neural Networks and Fuzzy Models; Springer: Berlin, Germany, 2001.

20. Imal, E. CDM based controller design for nonlinear heat exchanger process. Turk. J. Electr. Eng. Comput. Sci. 2009, 17, 143-161.

21. Skrjanc, I.; Matko, D. Predictive functional control based on fuzzy model for heat-exchanger pilot plant. IEEE Trans. Fuzzy Syst. 2000, 8, 705-712.

22. Hooshang Mazinan, A.; Sadati, N. Fuzzy predictive control based multiple models strategy for a tubular heat exchanger system. Appl. Intell. 2010, 33, 247-263.

23. Badgwell, A.B.; Qin, S.J.; Kouvaritakis, B. Review of nonlinear model predictive control applications. IEE Control Ser. 2001, 3, 3-32.

24. Parker, R.S.; Gatzke, E.P.; Mahadevan, R.; Meadows, E.S.; Kouvaritakis, F.J.; Doyle, B. Nonlinear model predictive control: Issues and applications. IEE Control Ser. 2001, 5, 34-57.

25. Llorente García, I.; Álvarez, J.L.; Blanco, D. Performance model for parabolic trough solar thermal power plants with thermal storage: Comparison to operating plant data. Sol. Energy 2011, $85,2443-2460$.

26. Niknia, I.; Yaghoubi, M. Transient simulation for developing a combined solar thermal power plant. Appl. Therm. Eng. 2012, 37, 196-207.

27. Rolim, M.M.; Fraidenraich, N.; Tiba, C. Analytic modeling of a solar power plant with parabolic linear collectors. Sol. Energy 2009, 83, 126-133.

28. Powell, K.M.; Hedengren, J.D.; Edgar, T.F. Dynamic optimization of a solar thermal energy storage system over a $24 \mathrm{~h}$ period using weather forecasts. In Proceedings of the American Control Conference, Washington, DC, USA, 17-19 June 2013; pp. 2946-2951.

29. Powell, K.M.; Edgar, T.F. Modeling and control of a solar thermal power plant with thermal energy storage. Chem. Eng. Sci. 2012, 71, 138-145.

30. Kibaara, S.; Chowdhury, S.; Chowdhury, S.P. Analysis of Cooling Methods of Parabolic Trough Concentrating Solar Thermal Power Plant. In Proceedings of the 2012 IEEE International Conference on Power System Technology, Auckland, New Zealand, 30 October-2 November 2012; pp. 1-6.

31. Solar Advisor Model. Available online: https://sam.nrel.gov (accessed on 24 July 2014).

32. Martín, L.; Zarzalejo, L.F.; Polo, J.; Navarro, A.; Marchante, R.; Cony, M. Prediction of global solar irradiance based on time series analysis: Application to solar thermal power plants energy production planning. Sol. Energy 2012, 84, 1772-1781.

33. Fraser, K.F.; Hollands, K.G.T.; Brunger, P. An empirical model for natural convection heat exchangers in SDHW systems. Sol. Energy 1995, 55, 75-84. 
34. Vera-García, F.; García-Cascales, J.R.; Gonzálvez-Maciá, J.; Cabello, R.; Llopis, R.; Sanchez, D.; Torrella, E. A simplified model for shell-and-tubes heat exchangers: Practical application. Appl. Therm. Eng. 2010, 30, 1231-1241.

35. Ravagnani, M.A.S.S.; Caballero, J.A. A MINLP model for the rigorous design of shell and tube heat exchangers using the tema standards original. Chem. Eng. Res. Des. 2007, 85, 1423-1435.

36. Green, D.W.; Perry, R.H. Perry's Chemical Engineer's Handbook, 6th ed.; McGraw-Hill: New York, NY, USA, 1984; Sections 10-11.

37. Kakaç, S.; Liu, H. Heat Exchangers, Selection, Rating and Thermal Design; CRC Press: Boca Raton, FL, USA, 1995; p. 53.

38. Peters, M.S.; Timmerhaus, K.; West, R.E. Plant Design and Economics for Chemical Engineers, 5th ed.; McGraw-Hill Professional: New York, NY, USA, 2003; pp. 716-724.

39. Tan, X.H.; Zhu, D.S.; Zhou, G.Y.; Yang, L. 3D numerical simulation on the shell side heat transfer and pressure drop performances of twisted oval tube heat exchanger. Int. J. Heat Mass Transf. 2013, 65, 244-253.

40. You, Y.; Fan, A.; Huang, S.; Liu, W. Numerical modeling and experimental validation of heat transfer and flow resistance on the shell side of a shell-and-tube heat exchanger with flower baffles. Int. J. Heat Mass Transf. 2012, 55, 7561-7569.

41. You, Y.; Fan, A.; Lai, X.; Huang, S.; Liu, W. Experimental and numerical investigations of shell-side thermo-hydraulic performances for shell-and-tube heat exchanger with trefoil-hole baffles. Appl. Therm. Eng. 2013, 50, 950-956.

42. Zukauskas, A. Heat transfer from tubes in crossflow. In Advances in Heat Transfer; Irvine, T.F., Jr., Hartnett, J.P., Eds.; Academic Press, Inc.: New York, NY, USA, 1987; Volume 18, pp. 87-159.

(C) 2014 by the authors; licensee MDPI, Basel, Switzerland. This article is an open access article distributed under the terms and conditions of the Creative Commons Attribution license (http://creativecommons.org/licenses/by/4.0/). 